\title{
Strengthening of Burri box Girder Bridge by using External post Tensioning Technology (Sudan)
}

\author{
Eltyeb Elrayah Khalafala ${ }^{1, *}$ and Ismail A Talaat ${ }^{2}$ \\ 1 Span Engineering Consultancy, Khartoum, Sudan \\ 2 International University of Africa, Khartoum, Sudan \\ * Corresponding author: Eltyeb Elrayah Khalafala (e-mail: Eekhalafalla@yahoo.com).
}

Article history: Received 14 March 2020, Received in revised form 4 November 2020, Accepted 11 November 2020

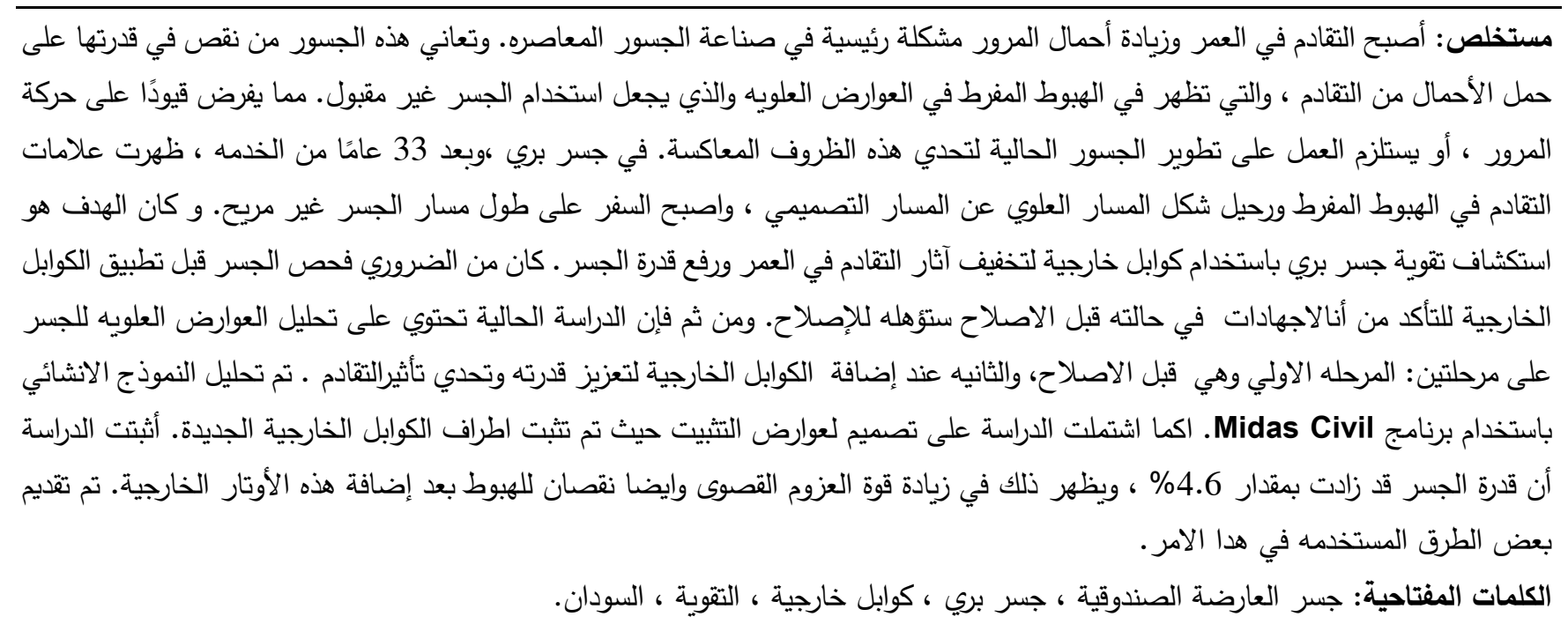

ABSTRACT Ageing, and increasing traffic loads, has become a major problem into today bridge industry. These bridges go deficiency in its Load Carrying Capacity from ageing, exhibited in excessive deformation which renders the bridge usage to an unacceptable level. These will either, impose traffic restriction, or upgrading the existing bridges to defy these adverse conditions. At Burri Bridge, after 33 years on operation, signs of ageing showed in the excessive deformation and the departure of the deformed shape of the super structure from the design profile, and travelling along the bridge was un-comfortable and difficult trip riding. The Objective was to explore the strengthening of the Burri Bridge by using external post tensioned tendons to mitigate the ageing effects and to elevate the capacity of the bridge. It was requisite to examine the bridge before the application of external tendons to insure the stresses in its past status will qualify it for repair. Hence, the present study contains the analysis of the Bridge superstructure in two stages. The first is done in its Past status, and the second when external tendons are added to boost its capacity and defy the effect of past load level, and a new standard load tested. The model was analyzed using Midas Civil software. The study includes the design of the anchor beams where the fresh external tendons are terminated. The study proved that, the capacity of the Bridge is increased by $4.6 \%$, and this is interpreted in the increase of the Ultimate Flexural Strength and the decrease of the deformation after adding these external tendons. Some of the Techniques implemented are presented.

Keywords: Box Girder Bridge, Burri Bridge, External tendons, Strengthening, Sudan.

\section{INTRODUCTION}

In 1972 a Free Cantilever Method bridge type was constructed at the Blue Nile River connecting Khartoum with Khartoum North Fig. 1.The length 
of the bridge is $519.6 \mathrm{~m}$. The spans of the bridge excluding the approaching bays were seven spans $(43.3 \mathrm{~m}+5 \times 86.6 \mathrm{~m}+43.3 \mathrm{~m})$ with post -tension non-uniform hinged T-shaped rigid frame box girders.

After 33 years on operation the bridge showed signs of ageing exhibited in the excessive deformation and the departure of deformed shape of the super structure from the design profile of the bridge that made the travelling along the bridge un-comfortable, and difficult trip riding.

On March 2005 [1] a report addressed the physical inspection, computational analysis and load tests, and call for demand for repair was submitted. Among many other findings, the deflection of the cantilever end was $11.9 \sim 20.4 \mathrm{~cm}$ which is excessive and the reason for it, is due to the concrete creep and relaxation of pre-stressed tendons.

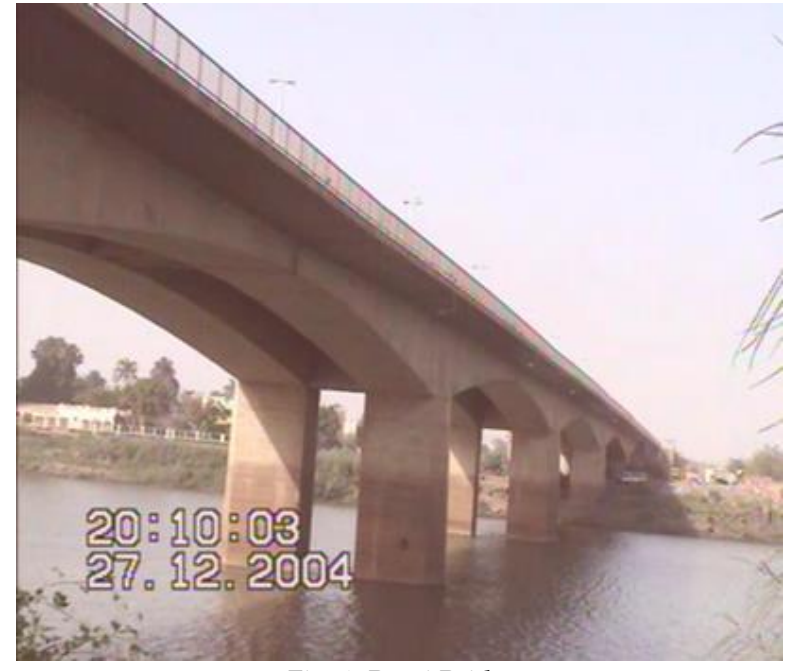

Fig. 1: Burri Bridge

In 2012 [2], it was decided to elevate and increase the capacity of the bridge. Out of many proposals the post tensioning technology was the most appealing one. The prerequisite to go for maintenance were the current stresses in the concrete either tension/compressive stresses does not exceed the allowable level, and there is a room for further increase in these stresses, additionally the tensile stresses in existing tendons are within the allowable limits. .

Analysis was run in two stages, the first stage of analysis was conducted to isolate and have knowledge on the effect of the ageing after 33 years the bridge in operation and to quantify the value of the compressive stresses that will allow refurbishment and the compressive stresses developed should be below the controlled compressive stress of $26.30 \mathrm{MPa}$ under the demand of HL-93 [1]. Additionally, the tensions in the existing tendons were examined to confirm the tensions in these tendons are below the allowable limits. Further on, the ultimate flexural strengths of selected sections were computed. In the second round of the analysis, eight numbers of external tendons confirming to ASTM416/416M-06 [3] were added and the compressive stresses were recalculated to confirm that it is within the controlled limits. Further the ultimate strengths of selected sections were computed to compare the increase in the loading capacity of the bridge before and after application of the external tendons alongside the deformed shape of the box girder

\section{EXTERNAL PRE-STRESSING [4],[5]:}

External post-tensioning is one of the widely used strengthening techniques that can be used to mitigate the adverse effects due to ageing and to boost the carrying capacity of box girder bridges due to its advantages. It refers to a pre-stressing technique where the pre-stressing tendons are placed outside the concrete section and the pre-stressing force is transferred to the concrete by means of end anchorages, deviators and saddles.

Today, external pre-stressing is considered one of the most powerful techniques for strengthening or rehabilitating existing concrete bridge structures. Also, because of the construction speed and economy associated with the use of external tendons, it is becoming popular in the construction of new concrete bridges.' Several evaluations of existing bridges which were either constructed or strengthened using external tendons, together with the results of limited experimental studies on external pre-stressing, have been reviewed and best described by Virlogeux'and, more recently, have been emphasized by Rabbat, and Solat [6].

Some of the advantages include:

- More economical construction

- Easier tendon layout, placement and consolidation of concrete

- Better corrosion protection as compared to a conventional tendon system 
The use of an external tendon system to strengthen existing concrete bridges is conceptually different from that used in the traditional design and construction of new bridges. In the design of new concrete bridges, external tendons constitute the primary reinforcement; hence, the analysis and design could be achieved using methods similar to un-bonded post-tensioned construction. When used for strengthening, however, external tendons represent only a part of the total flexural reinforcement. The remaining reinforcement could be mild reinforcing steel, internal pre-stressing steel, or a combination of both, depending on the type of concrete structural system to be rehabilitated. Also, more important, the level of the externally applied load and the extent of deformation (crack widths and deflections) at which external pre-stressing is utilized to strengthen existing concrete structural members differs from those when used in the design of new concrete members. The corresponding difference makes the assessment of the advantages of external pre-stressing with regard to the structural behavior different in both cases [6]

\subsection{Scope}

The scope of this paper includes the design and analysis when external post tensioned system is implemented. The paper will cross reference the output obtained with the maintenance report issued on 2012 [2]. Eight External Post Tensioned tendon of 270 low -relaxation stranded wire was used complying to ASTM A416. Its standard Tensile strength is $1860 \mathrm{MPa}$ and the cable size was $10 \varnothing 115.24$ non-cohesive steel pre-stressed bundle, its stretching control stress $1116 \mathrm{MPa}$.

Six Tendons were terminated and anchored at $24.05 \mathrm{~m}$ from the Centre of the Pier on both sides and the other two tendons were terminated at $39.05 \mathrm{~m}$ from the center of the bridge pier.

\section{BURRI BRIDGE DATA [7[}

\subsection{Cross Sections Geometry}

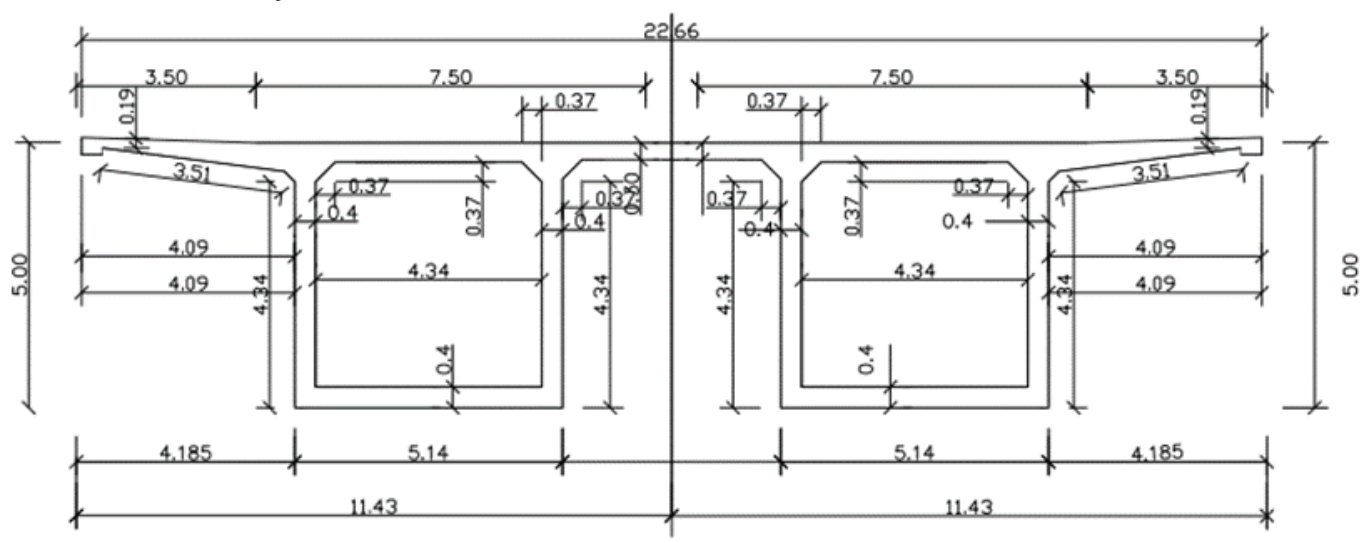

Fig. 2: Section of bridge at Pier Table

The depth of the box girder at end of cantilever is $1.6 \mathrm{~m}$

\subsection{Material properties and allowable stresses}

\section{A- Stresses Limits in concrete at service}

From site tests $f c u=47.4 \mathrm{~N} / \mathrm{mm}^{2}$

fcu to (cylinder strength) $f c^{\prime}=43.844 \mathrm{~N} / \mathrm{mm}^{2}$

Initial $\mathrm{f} c i=0.8 \times \mathrm{xc}^{\prime}=35 \mathrm{~N} / \mathrm{mm}^{2}[10]$

$f c i$ specified compressive strength of concrete at the time of prestressing

Modulus of elasticity $=4800 \sqrt{ } f_{c^{\prime \prime}}=31.78 \mathrm{MPa}$

Allowable Stresses Limits in concrete at service

Compression

After All losses $\quad f_{c a}=0.6 \mathrm{fc}^{\prime}=26.3 \mathrm{~N} / \mathrm{mm}^{2}$

\section{Tension}

Immediately after pre-stressing

$$
=0.25 \sqrt{ } f_{\mathcal{C}^{\prime}} \quad=1.655 \mathrm{~N} / \mathrm{mm}^{2}
$$

After pre-stressing $\quad=0.289 \sqrt{ } f c^{\prime}=1.90 \mathrm{~N} / \mathrm{mm}^{2}$

B Tendons Material [3].

Internal bonded tendons as A416- 270 (low relaxation) $12 \varnothing 112.7 \mathrm{~mm}\left(.5^{\prime \prime}\right)$

Ultimate strength $f p u=1863 \mathrm{~N} / \mathrm{mm}^{2}$

Yield Strength fpy $=1569 \mathrm{~N} / \mathrm{mm}^{2}$

Area of single tendon $A p=1184.25 \mathrm{~mm}^{2}$

Induced post tension (Jacking)

$f p j=0.72 \mathrm{fpu}=1341 \mathrm{~N} / \mathrm{mm}^{2}$ 
Anchorage Slip

Friction losses

$\Delta \mathrm{S}=6 \mathrm{~mm}$

Wobble losses

$\mu=0.3 \mathrm{rad}$

$\mathrm{K}=.006 / \mathrm{m}$

External un-boned tendons as A416- 270 [3]

(Low relaxation)10ǿ15.2mm (.6")

Ultimate strength $f p u=1863 \mathrm{~N} / \mathrm{mm}^{2}$

Yield Strength $\quad f p y=1569 \mathrm{~N} / \mathrm{mm}^{2}$

Ultimate strength $f p u=1863 \mathrm{~N} / \mathrm{mm}^{2}$

Yield Strength $f p y=1569 \mathrm{~N} / \mathrm{mm}^{2}$

Area of single tendon $A p=1387 \mathrm{~mm}^{2}$

Induced post tension (Jacking)

$$
f p j=0.72 f p u=13 \mathrm{~N} / \mathrm{mm}^{2}[3]
$$

\section{Results}

4.1 Computed Results of Stresses before repair.

On the application of the HL93 on the bridge model, the ultimate combined compressive stress inclusive the time dependent effects was a compressive stress of $-13.5 \mathrm{MPa}$ located at the top of the piers, see fig. 1 .

Similarly, the maximum compressive stress due to this combination at service limit state was $11.30 \mathrm{MPa}$

\subsection{Tension Stresses in the Bonded Tendons.}

The bridge box girder has 294 bonded tendons, distributed and laid out according to the designer set of the drawing [4].Consequently, only part of these tendons is investigated in this study, and was selected carefully to represent the utmost values of tension that expected to happen any time during its operation. Table 1,exhibit the maximum tension in the bonded tendons at the piers top where it is expected the maximum tension in these tendons are gained due the cantilever action.

TABLE 1: TENSION STRESSES IN BONDEDTENDONS AT PIERSTABLE AFTER 33 YEARS IN OPERATION

\begin{tabular}{|c|c|c|c|c|c|c|}
\hline & \multicolumn{2}{|c|}{ Tension stresses in Tendons } & \multicolumn{2}{c|}{ Allowable Stress limits in tension stress in } \\
tendons \\
\hline $\begin{array}{c}\text { Tendon } \\
\text { Name }\end{array}$ & $\begin{array}{c}\text { f_p1 } \\
\left(\mathrm{N} / \mathrm{mm}^{\wedge} 2\right)\end{array}$ & $\begin{array}{c}\text { f_p2 } \\
\left(\mathrm{N} / \mathrm{mm}^{\wedge} 2\right)\end{array}$ & $\begin{array}{c}\text { f_pe } \\
\text { (N/mm^2) }\end{array}$ & Immediately after anchor set & At service \\
\hline Col.1 & Col 2 & Col 3 & Col 4 & $\begin{array}{c}\text { Col } 5 \\
\text { At anchor. }\end{array}$ & $\begin{array}{c}\text { Away from } \\
\text { anchor }\end{array}$ & Col 7 \\
\hline TOP01-01 & 1144.69 & 1245.43 & 1094.50 & 1304.28 & 1378.81 & 1242.6 \\
\hline TOP01-01' & 1224.80 & 1245.32 & 1060.06 & 1304.28 & 1378.81 & 1242.6 \\
\hline TOP01-02 & 1144.69 & 1245.43 & 1094.50 & 1304.28 & 1378.81 & 1242.6 \\
\hline TOP01-02' & 1224.80 & 1245.32 & 1060.06 & 1304.28 & 1378.81 & 1242.6 \\
\hline TOP01-03 & 1144.69 & 1245.43 & 1098.54 & 1304.28 & 1378.81 & 1242.6 \\
\hline
\end{tabular}

f_p1 $\left(\mathrm{N} / \mathrm{mm}^{2}\right)$ : Maximum stress in tendon at both anchorages immediately after anchor setCol.1

$f \_p 2\left(\mathrm{~N} / \mathrm{mm}^{2}\right)$ : Maximum stress in tendon along the length of the member away from the anchorages immediately after anchor set (only for post-tensioning) col. 2

f_pe $\left(\mathrm{N} / \mathrm{mm}^{2}\right)$ Tension stress in tendon after all lossesCol.7

\subsection{Deformed shape of the super structure before} laying External Tendons

The Burri Bridge was constructed in eleven construction stages. The maximum deformation occurred at the construction stage designated as CS11. The value of the down ward deformation calculated from the model was $158 \mathrm{~mm}$ at the ends of the cantilevers. The measured deformation from site were ranging between 110 to $204 \mathrm{~mm}$ [1]

\subsection{Enhanced Deformation for bridge after \\ Strengthening}

The enhanced of the superstructure deformed shape of the bridge shown graphically in Fig. 3, and the computed maximum deflection was -100 $\mathrm{mm}$ against the computed one of $-158 \mathrm{~mm}$ before laying the external tendons.

TABLE. 2 DEFLECTION AT AFTER 33 YEARS IN OPERATION

\begin{tabular}{|l|l|l|}
\hline $\begin{array}{c}\text { Construction } \\
\text { Stage No }\end{array}$ & $\begin{array}{l}\text { Calculated } \\
\text { Deflection } \\
\text { by Model }\end{array}$ & $\begin{array}{l}\text { Measured } \\
\text { Deflection [1] }\end{array}$ \\
\hline CS11 & $158 \mathrm{~mm}$ & 119 to $204 \mathrm{~mm}$ \\
\hline
\end{tabular}




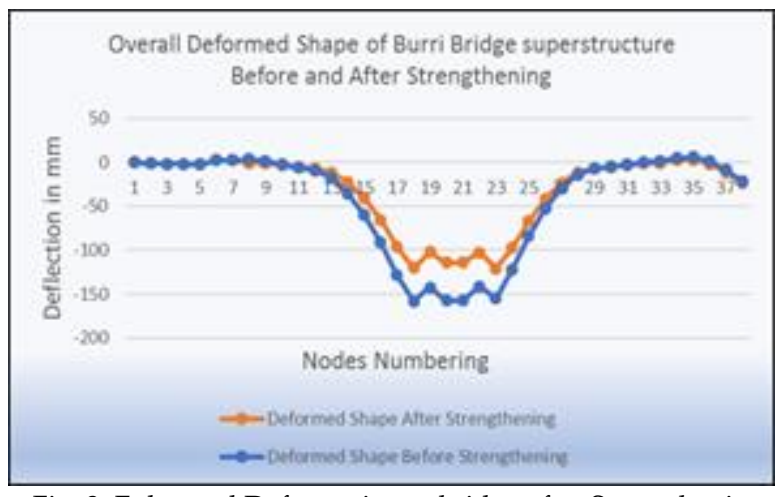

Fig. 3: Enhanced Deformation at bridge after Strengthening

\subsection{Computed tension stress in tendons after laying} the external tendons.

The tension stress in the external tendons (eight tendons in each voided area of Burri Bridge) were computed, in addition to the tension stresses in the existing bonded tendons

Samples of the computed tensions stresses in these tendons are displayed in Table 3. The tension stresses in the applied External tendons after all losses f_pe was $1116.8 \mathrm{MPa}$ (col.4) against the allowable stresses of $1339 \mathrm{MPa}$ (col7) on the same table.

Similarly, the tension stresses are tabulated on part of the bonded tendons. The f_pe tension stresses after losses in these tendons was 1084.8 $\mathrm{MPa}(\mathrm{Col} .4)$ which is less than $1242.6 \mathrm{MPa}(\mathrm{Col} .7)$.

TABLE 3: COMPUTED TENSION STRESS IN TENDONS AFTER THE APPLICATION OF EXTERNAL TENDONS (MPA)

\begin{tabular}{|c|c|c|c|c|c|c|c|c|}
\hline \multicolumn{9}{|c|}{ Tendon Stress Limit Check After Adding External Tendons } \\
\hline & & \multirow{3}{*}{$\begin{array}{l}\text { Tendon } \\
\text { Name }\end{array}$} & \multicolumn{3}{|c|}{ Computed Tendon Stress } & \multicolumn{3}{|c|}{ Tendon Stress Limit } \\
\hline & & & \multirow{2}{*}{$\begin{array}{c}f \_p 1 \\
\left(\mathrm{~N} / \mathrm{mm}^{\wedge} 2\right)\end{array}$} & \multirow{2}{*}{$\begin{array}{c}f \_p 2 \\
\left(\mathrm{~N} / \mathrm{mm}^{\wedge} 2\right)\end{array}$} & \multirow{2}{*}{$\begin{array}{c}f \_p e \\
\left(\mathrm{~N} / \mathrm{mm}^{\wedge} 2\right)\end{array}$} & \multicolumn{2}{|c|}{ Immediately after anchor set } & \multirow{3}{*}{$\begin{array}{c}\text { At service } \\
7\end{array}$} \\
\hline & & & & & & \multirow{2}{*}{5 At anch. } & \multirow{2}{*}{6 Away from anch. } & \\
\hline & & 1 & 2 & 3 & 4 & & & \\
\hline \multirow{5}{*}{ 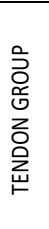 } & \multirow{5}{*}{ 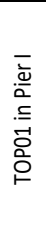 } & TOP01-01 & 1144.6925 & 1245.4345 & 1084.0975 & 1304.282 & 1378.8124 & 1242.6 \\
\hline & & TOP01-01' & 1224.8044 & 1245.3223 & 1054.4426 & 1304.282 & 1378.8124 & 1242.6 \\
\hline & & TOP01-02 & 1144.6925 & 1245.4345 & 1084.0979 & 1304.282 & 1378.8124 & 1242.6 \\
\hline & & TOP01-02' & 1224.8044 & 1245.3223 & 1054.4427 & 1304.282 & 1378.8124 & 1242.6 \\
\hline & & TOP01-03 & 1144.6925 & 1245.4345 & 1087.8705 & 1304.282 & 1378.8124 & 1242.6 \\
\hline \multirow{8}{*}{ 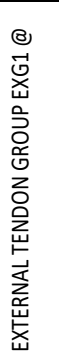 } & \multirow{8}{*}{$\overline{\text { 饪 }}$} & EXG1/1 & 1021.2891 & 1116.6733 & 1116.6733 & 1304.282 & 1378.8124 & 1339.20 \\
\hline & & EXG1/2 & 1021.4215 & 1116.8057 & 1116.8057 & 1304.282 & 1378.8124 & 1339.20 \\
\hline & & EXG1/3 & 1021.2897 & 1116.6739 & 1116.6739 & 1304.282 & 1378.8124 & 1339.20 \\
\hline & & EXG1/4 & 1021.29 & 1116.6742 & 1116.6742 & 1304.282 & 1378.8124 & 1339.20 \\
\hline & & EXG1/5 & 1021.2903 & 1116.6745 & 1116.6745 & 1304.282 & 1378.8124 & 1339.20 \\
\hline & & EXG1/6 & 1021.2906 & 1116.6748 & 1116.6748 & 1304.282 & 1378.8124 & 1339.20 \\
\hline & & EXG1/7 & 1021.4244 & 1116.8086 & 1116.8086 & 1304.282 & 1378.8124 & 1339.20 \\
\hline & & EXG1/8 & 1021.2912 & 1116.6754 & 1116.6754 & 1304.282 & 1378.8124 & 1339.20 \\
\hline
\end{tabular}

\section{DISCUSSION ON THE ANALYSIS RESULTS}

We can conclude that when strengthening Burri Bridge by external tendons After 33 years on operation the following noticed

The effect of the moving loads is not contributing much to the service stresses. At the top center of the piers, the compressive stress due to live load alone was-1.74 $\mathrm{MPa}$, compared to the overall compressive stress of $-11.30 \mathrm{MPa}$, inclusive the time dependent effects.

The maximum, compressive stresses at service of value $-11.30 \mathrm{MPa}$ is below the controlled limit of -26.3 MPa which qualify Burri Bridge for upgrading safely [1], [2].

The maximum tension stresses in the existing tendons before application of the external tendons was f_pe $=1098 \mathrm{MPa}$, which is less than the limiting tension stresses of $1242.6 \mathrm{MPa}$, confirming to proceed for upgrading .see table 1

On the application of the external Tendons, the result showed that the deformed shape profile of the super structure was enhanced and the smooth riding trips will be achieved. The vibration which was induced by the excessive deflection at the ends of the cantilevers will diminish due to the cutback in this deflection. 
The Load carrying capacity of Burri Bridge was elevated, and this is interpreted in the increase of the Ultimate Flexural Strength after adding the external tendons. which is displayed in Fig 4

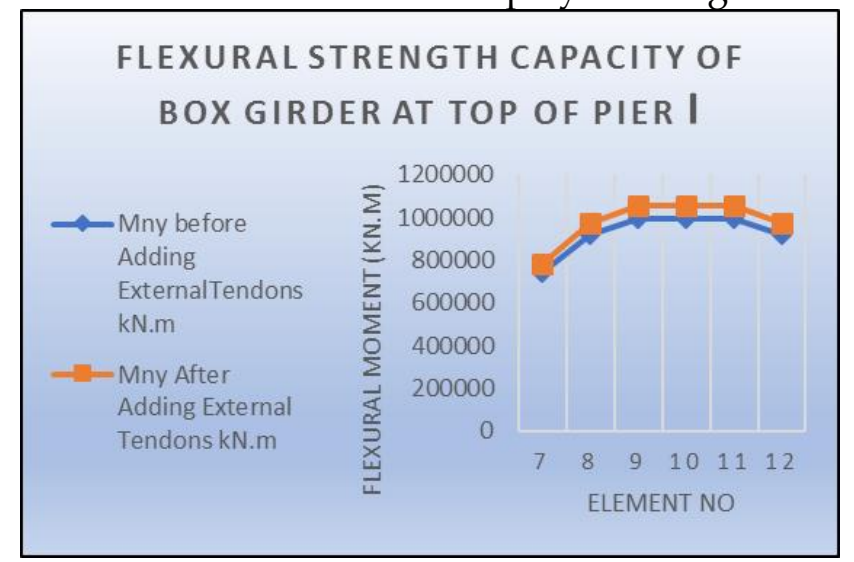

Fig. 4: Flexural Strength Mny at Top of Piersbefore and after Laying the External Tendons

The amount of increase observed in the Burri Model was ranging between $36,000 \mathrm{kN} . \mathrm{m}$ to $50,000 \mathrm{kN} . \mathrm{m}$ which amount to $4.6 \%$

The maximum compressive stresses value after adopting the external tendons - was -20.02 MPa. This value was less than the allowable stress which is $-26.3 \mathrm{MPa}$. This value meets the requirements of AASHTO LRFD [9]. Also, the results showed that no tensile stresses occurred and its values were zero, and it can be welldefined that the condition of controlling the stresses when adding external tendons is met.

It can be observed from Table 3 the tension stress in the External Tendons after all losses for the Group EXG1 composing of eight tendons EXG1/1 to EXG1/8, f_pe $=1116.80 \mathrm{MPa}<1339.20$ $\mathrm{MPa}<$ allowable limits. Further the tension stresses in the selected Group TOP G1ofthe bonded tendons remained below the allowable limit specified

\section{THE DESIGN OF ANCHOR BEAMS}

These anchorage beams are connected to the bridge body by embedded shear connectors. The depth of these anchor beams is $1.5 \mathrm{~m}$ and the connectors are laid in rows at $150 \mathrm{~mm}$ apart. The number of the shear connectors at the anchor beam where the six tendons were terminated was 600, and 490, where the remaining two terminated [2].

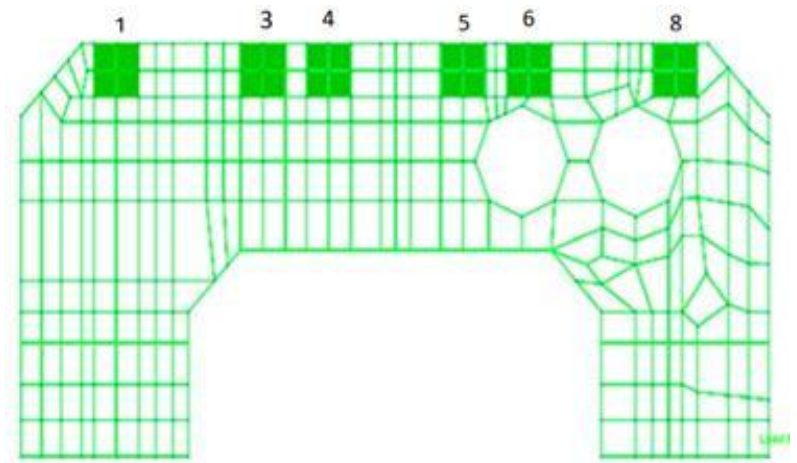

Fig. 5: Anchor beam model for six Tendons 2

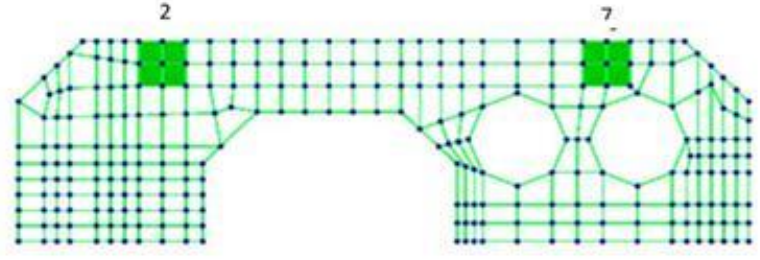

Fig. 6: Anchor beam model for Two Tendons

From the analysis by Midas software the force in the external tendons immediately after the anchor set $=$ stress in tendon $\mathrm{x}$ area of tendon $=1021 \mathrm{x} \mathrm{Ap}$

Thus, the force is transmitted to the anchor set by base plate of $0.36 \mathrm{~m} \times 0.36 \mathrm{~m}$

Area of application $=0.36 \times 0.36=0.1296 \mathrm{~m}^{2}$

The pressure on the base plate is

$$
=1419.2 /(0.36 \times 0.36)=10950 \mathrm{kN} / \mathrm{m}^{2}
$$

In anchor beam I the reactions from the external tendons applied in group to simulate the actual condition during construction

Group $1=$ Tendon $1+$ Tendon 8

Group 2= Group1 +(Tendon 3+Tendon 6)

Group 3=Tension in all tendons simultaneously Under these combinations the maximum force was $\mathrm{Fz}=-112.827 \mathrm{kN}, \mathrm{Fy}=21.239 \mathrm{kN}$,

Resultant force $=\sqrt{112.82^{2}+21.23^{2}}=114.85 \mathrm{kN}$

The shear capacity of imbedded connector:

Diameter of rebar diameter $20 \mathrm{~mm}$

Area for single shear connector $=314 \mathrm{~mm}^{2}$

Capacity of single connector

$$
\begin{aligned}
& =314 \times 460 / 1000 \\
& =144.44 \mathrm{kN}>\text { actual reaction of } 114.85 \mathrm{kN}
\end{aligned}
$$

It can be concluded that the shear connectors at Anchor Beam I is satisfactory. Similarly, the same procedure was imposed for anchor beam II with two external tendons termination and the result was satisfactory

\section{STRENGTHENING PERFORMED ON SUPER-STRUCTURE [2].}

The strengthening performed on the bridge 
superstructure included injection and repair of cracks in concrete, enlargement of walls of box beams and external pre-stressing of additional cables. Figs 7, 8, 9 show some of these activities

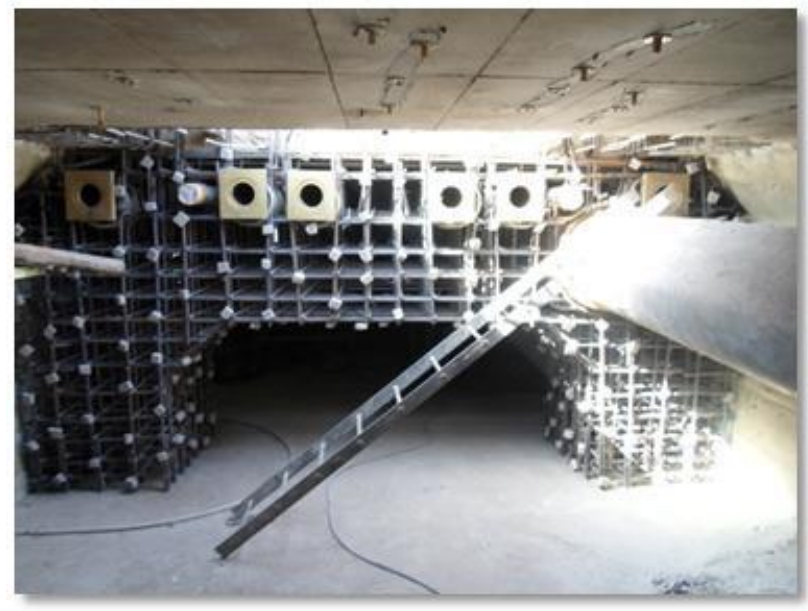

Fig. 7: Anchor Beam for six Tendons termination

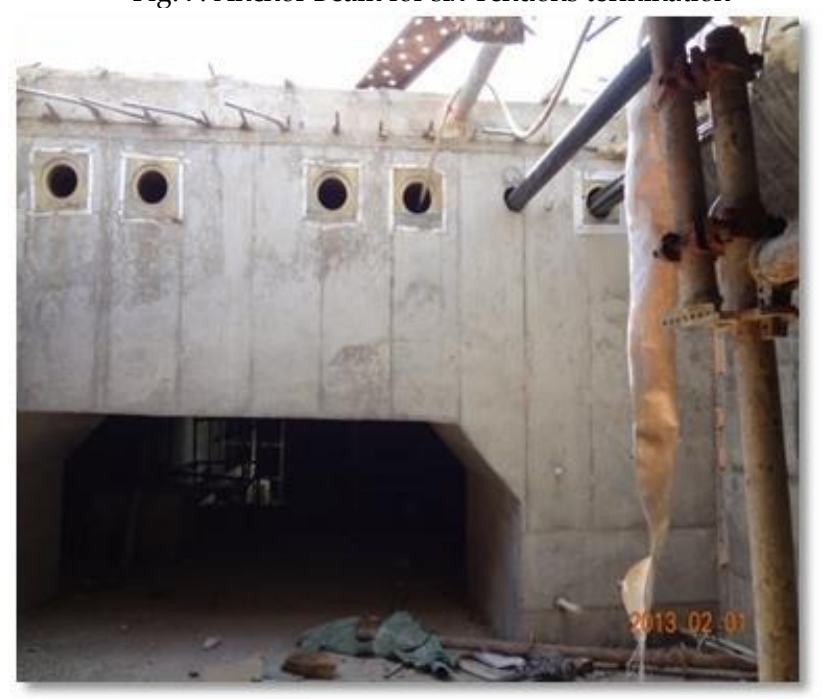

Fig. 8: Tendons laying

\section{CONCLUSIONS}

The conclusions depicted from the study rehabilitation of Burri Bridge are listed below:

1) Time dependent effects is an imminent phenomenon in the box girder bridges industry, that cannot be avoided and should be considered in a serious way to lessen it.

2) The strengthening can only undergo if it is evident that the current stresses in the bridge sections, and the tendons tension stress will allow these procedures.

3) The Load carrying capacity of the Bridge can be elevated, and this is interpreted in the increase of the Ultimate Flexural Strength after adding external tendons.

4) The deformed superstructure profile. is enhanced, and the vibration which was induced by the excessive subsidence in Burri bridge will diminish due to the cutback in this deflections.

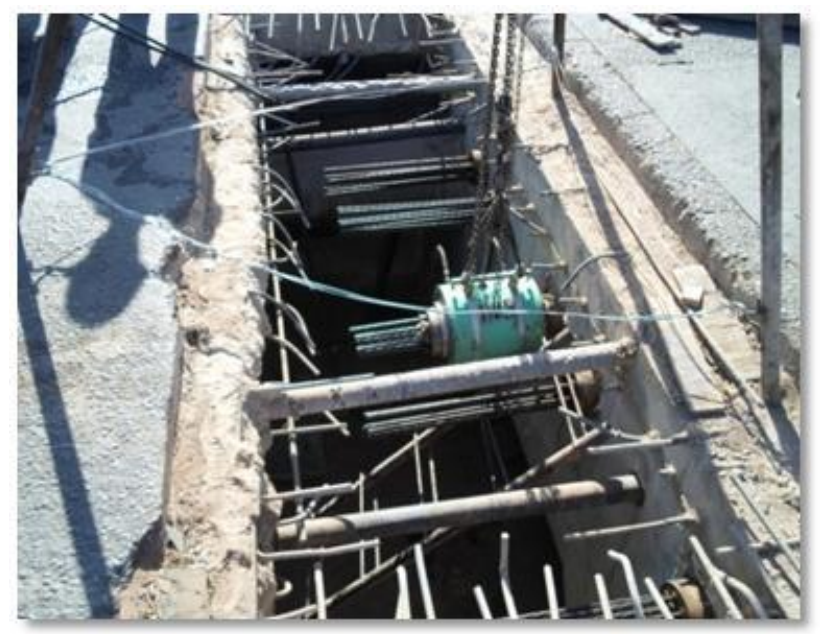

Fig. 9: Tendons external prestressing

5) A reserve was generated after adding the External Tendon and this was apparent when the Model was examined under the Caltrans P-5

6) The number of construction stages play a big role in the behavior of the box girder bridge. The more construction stages, the more adverse effect of the time depending material.

7) The increase in ultimate flexural strength, will be accompanied by increase in the concrete sections compressive stress, this relation is controlled by the number of cables, and its area. Accordingly, an iteration process is requisite to reach an optimum status.

8) In a Newly RC Box Girder bridge, it is recommended to make a provision for future external tendons application to cater for the ageing effects. This can be achieved by casting in situ anchor blocks to accommodate the external tendons in the future.

\section{REFERENCES}

[1] Longjain Road and Bridge Co, Ltd. P R China, "Report Test of Burri Bridge", March 20, 2005.

[2] Longjain Road and Bridge Co, Ltd .Design and Construction Drawings for Maintenance and Reinforcement" Burri Bridge April 2012.

[3] ASTM Designation A 416/A416M-06 "Standard Specification For Steel Strand, Uncoated Seven-Wire For Pre-stressed Concrete" 2006

[4] Ministry of Local Government (Sudan) Burri Bridge Design Drawing by S.T.I.P.E1972.

[5] Ali FadhilNaser and Wang Zonglin "Strengthening of Jiamusi pre-stressed concrete highway bridge by using external post-tensioning technology" (ARPN) Asian research publishing, journal of engineering and applied sciences 2010.

[6] HakanNordin "Strengthening structure with Externally Prestressed Tendons-Literature Review" Technical Report 
Lulea University of Technology 2005

[7] Mohamed H. Harajli "strengthening of concrete beams by external prestressing" PCI journal Nov.-Dec.1983

[8] CEB-FIP "Fib "Model Code for Concrete Structures ". International Federation of Structural Concrete (fib) 2010

[9] AASHTO "Lrfd Bridge Design Specifications" 6th Edition 2012

[10] A M Neville "Properties of Concrete". Longman Scientific and Technical Third Edition 199456.

Dr Eltayeb Elrayah Khalafalla, Place of birth Sudan, Mahmiaya, Gabrab.

Date of birth 30.05.1954.

1. PhD Civil Engineering (Structures), University of Surrey-U. K. 1994.

2. M. Sc. Structural Engineering (with Distinction), University of Surrey-U. K. 1982.

3. B. Sc. Honours, University of Khartoum, Sudan 1979.

He held many positions in the field of construction and academic institutes such as head department of civil engineering, university of Karary (Karay academy of technology). He was associate professor at Karay University. Consultant for many assessment projects in bridges and structures. He was a member of many evaluation committees for some programs of civil engineering departments in Sudan. Member of some arbitration committees. He published two papers in the field of rehabilitation and strengthening of Structures.

Dr Eltayeb is amember of :

Sudan Engineering Society (Fellow).

Sudan Engineering Council (Consultant Engineer).

\section{Dr. Ismail Ahmed Taha Talaat}

Place of Birth: Atbara -Sudan

Education:

B.Sc. Civil Engineering Cairo University Cairo 1969.

Post Graduate Diploma in (Structural) Dundee University Scotland 1975

- MSc. (structural) Dundee University 1977

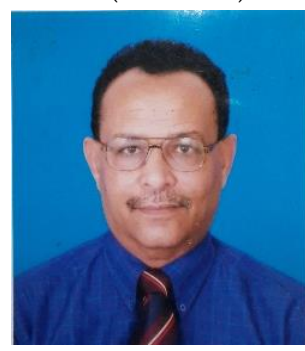

- Ph.D. (structural) Karary University

2016 Sudan

- Study course in dynamic of structure

St Reme' institute of Technology France 1982

Career Highlight

- Currently Head of Civil Engineering

Department, Faculty of Engineering, International University of Africa-Sudan

(IUA)

- AECOM ME, Al Ain, U.A.E. Head of Structural Engineering Department

- Parson Brinkerhoff (PB), Abu Dhabi, U.A.EStructural Design Group leader

- CETA Engineering (Denmark), Sudan. Projects Manager and Principle Structural Engineer

Title Dr. Talaat

Memberships

Member of the college engineering Council IUA

Member of college Engineering Scientific Research council IUA

Member of Sudanese engineering society 